\title{
A New Sensorless MRAS Based on Active Power Calculations for Rotor Position Estimation of a DFIG
}

\author{
Gil Domingos Marques and Duarte Mesquita e Sousa \\ Department of Electrical and Computer Engineering, IST, Technical University of Lisbon (TULisbon), 1049-001 Lisbon, Portugal \\ Correspondence should be addressed to Gil Domingos Marques, gil.marques@ist.utl.pt
}

Received 29 November 2010; Revised 3 March 2011; Accepted 25 March 2011

Academic Editor: Henry S. H. Chung

Copyright $\odot 2011$ G. D. Marques and D. Mesquita e Sousa. This is an open access article distributed under the Creative Commons Attribution License, which permits unrestricted use, distribution, and reproduction in any medium, provided the original work is properly cited.

\begin{abstract}
A sensorless method for the estimation of the rotor position of the wound-rotor induction machine is described in this paper. The method is based on the MRAS methodology and consists in the comparison of two models for the evaluation of the active power transferred across the air gap: the reference model and the adaptive model. The reference model obtains the power transferred across the air gap using directly available and measured stator variables. The adaptive model obtains the same quantity in function of electromotive forces and rotor currents that are measurable on the rotor position, which is under estimation. The method does not need any information about the stator or rotor flux and can be implemented in the rotor or in the stator reference frames with a hysteresis or with a PI controller. The stability analysis gives an unstable region on the rotor current dq plane. Simulation and experimental results show that the method is appropriate for the vector control of the doubly fed induction machine under the stability region.
\end{abstract}

\section{Introduction}

The Doubly fed Induction Generator (DFIG) is very attractive for Adjustable Speed Constant Frequency (ASCF) generators with limited speed range. In this system, the stator circuits of the wound induction machine are directly connected to the AC mains being the rotor circuits supplied by one back-to-back pulsewidth modulated (PWM) converter. This provides flexibility of operation in subsynchronous and supersynchronous speeds both in the generating and motoring modes. The rating of the power converter is determined by the operating speed range, normally limited to a $1 / 3$ under and above the synchronous speed [1] and is lower than the machine rating. This is the major advantage of the DFIG.

The conventional approach for the control of the DFIG is the implementation of stator flux orientation. The performance of the system depends on the knowledge of both the stator flux reference frame and the mechanical position of the rotor, derived from a position encoder as shown in Figure 1, or from a sensorless estimation algorithm as considered in this paper.
Since the power converter is connected to the rotor, it is mandatory to know the angular rotor position to implement the proposed control. Although the control is in the field reference frame, it is necessary to implement a reference frame transformation from the field to the rotor reference frame.

There are major challenges in designing a position sensorless for a doubly fed wound rotor induction machine. The algorithm should be stable and work well at any speed of the working range including near the synchronous speed. The rotor detection position system should be able to start on the fly, that is, it should converge to the correct position after some period of time, when the system starts working, without the knowledge of any initial condition [2].

There are several position sensorless methods proposed in the literature [2-16]. The earlier methods are proposed in [3-5]. In [3] a sensorless control method based in the control of the angle between a reference frame connected to the stator voltage or flux vector and the rotor current vector, was presented. The same authors presented a better solution based in a multiscalar model in [5]. The method proposed in [6] uses the rotor voltage and currents to design 


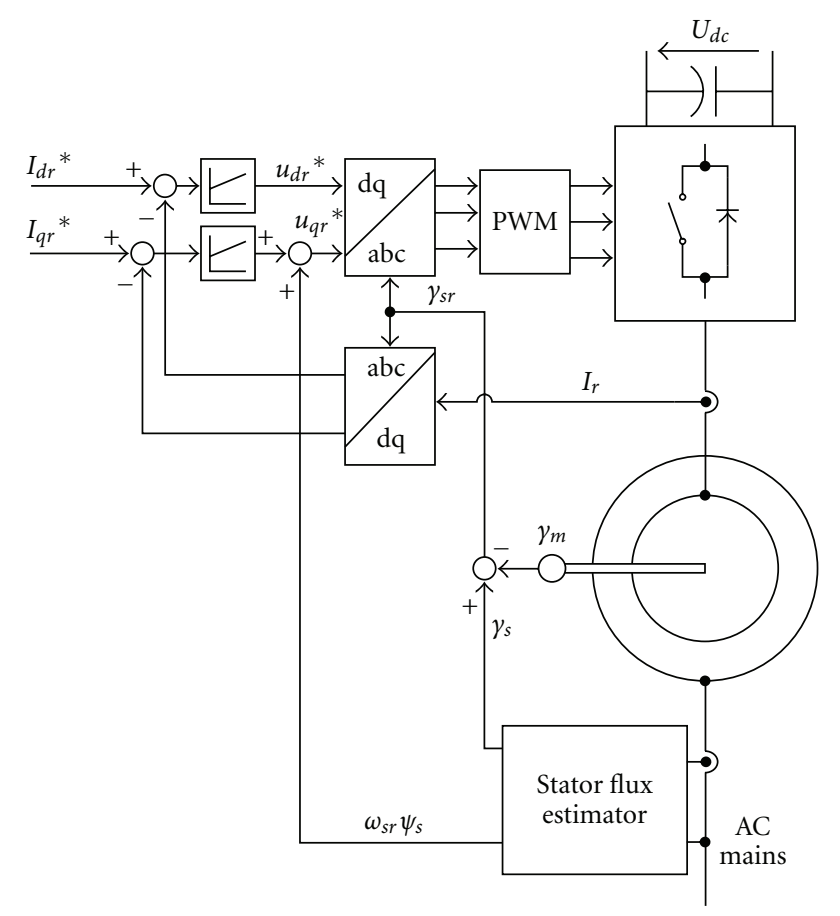

FIGURE 1: Block diagram for the implementation of field orientation.

a torque controller. It has problems near the synchronous speed because at this speed the rotor voltage is null. The scheme proposed in [7] is based on measurements of stator voltages, stator currents and rotor currents, and coordinate transformation. Similar principles are used in [8] to [16]. Rotor position detection systems, based in MRAS or PLL methodologies, are presented in [9-16], some working on the rotor reference frame [10-12] and others on the stator reference frame $[13,14]$. These methods are based on the phase comparison of an estimated quantity and its correspondent measured values. It is necessary to measure some variables in different reference frames. It was concluded that the best results are obtained when rotor currents are used [12]. In $[15,16]$ the PI control is replaced by a hysteresis controller, but the principles remain the same. Because the rotor current is used for phase comparison, the method is not satisfactory in the case of low load. In $[15,16]$ a limit of $15 \%$ of rated rotor current was established for acceptable performance.

This paper presents a new sensorless algorithm to detect the rotor position based on the Model Reference Adaptive System (MRAS) procedure. It is based on the comparison of active power transferred on the air gap computed in two different ways. The first, the reference model, is based on variables directly available in the stator circuits. The adaptive model uses the electromotive force, obtained using stator quantities, and the rotor current on the stator reference frame that is dependent on the rotor position because of the transformation from the rotor to the stator reference frame. The output of these two models is compared being its difference controlled using a PI or a hysteresis controller. It can be implemented in the stator or in the rotor reference

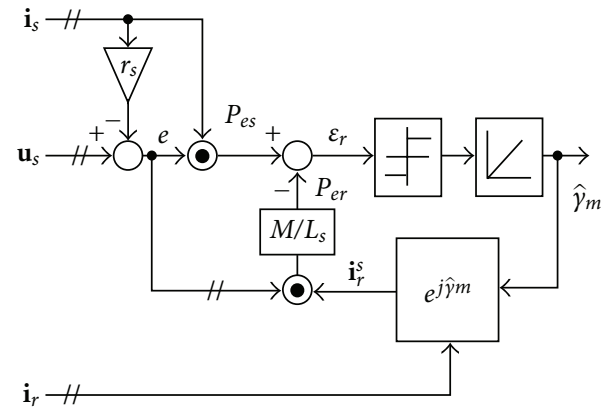

FIgURE 2: Rotor position estimator structure.

frame. All values used for the estimation of the rotor position are measured values. This gives some independence from the estimation of the stator flux necessary to implement stator flux orientation. The method is sensitive to only one parameter, but this sensibility is not important as it will be shown. A stability study is presented showing that the system has a stability region. It was determined in the laboratory that the method works with acceptable performance for low loads as low as $3 \%$ of the rated rotor current.

To simplify the description of the algorithm in this text and the implementation in the laboratory, per unit values are used. The angles are expressed in radians. The variable $P_{e}$ designates the active power that crosses the air gap. It can be computed in two different ways. When using the reference model the $P_{e s}$ symbol is adopted. Conversely, $P_{e r}$ is adopted on the adaptive model.

Section 2 describes the proposed algorithm. Section 3 presents the stability study and the condition for stability. The sensibility to parameters is presented on Section 4 where simulation results based in a tool constructed on the MatLab/Simulink environment are used. Section 5 presents experimental results obtained with a small prototype constructed for this purpose using a low price fixed point DSP. Section 6 presents the conclusions.

\section{Description of the Method}

To implement field orientation it is necessary to determine the position of the stator flux vector, and it is also necessary to determine the mechanical position of the rotor. This paper is devoted to a new procedure to determine the position of the rotor. The method analyzed in this paper is derived from the classical model of the induction machine.

The detection of the rotor position can be evaluated using the mechanism shown in Figure 2. Other sensorless methods use the flux estimation to determine the rotor position. In this paper the rotor angular position is obtained without the information of the stator flux leading to independent flux and rotor position algorithms.

2.1. Reference Model. Using the reference model, the power transferred across the air gap can be computed as

$$
P_{e s}=e_{\alpha} i_{\alpha s}+e_{\beta} i_{\beta s}-p_{f e},
$$


where

$$
\begin{aligned}
& e_{\alpha}=u_{\alpha s}-r_{s} i_{\alpha s}, \\
& e_{\beta}=u_{\beta s}-r_{s} i_{\beta s} .
\end{aligned}
$$

Equation (1) determines $P_{e s}$ using variables that are easily measurable and does not depend on the rotor position. The stator resistance has a relatively low importance because stator copper losses are small. The magnetic losses $p_{f e}$ should be estimated when low load operation is required, being assumed constant at rated voltage and frequency.

2.2. Adaptive Model. Using the adaptive model, the active power transferred across the air gap is computed by

$$
P_{e r}=-\frac{M}{L_{s}}\left(e_{\alpha} i_{\alpha r}^{s}+e_{\beta} i_{\beta r}^{s}\right),
$$

where the $\alpha \beta$ rotor currents, on the stator reference frame, are computed using the measured rotor currents and the estimated position

$$
\left[\begin{array}{c}
i_{\alpha r}^{s} \\
i_{\beta r}^{s}
\end{array}\right]=\left[\begin{array}{cc}
\cos \hat{\gamma}_{m} & -\sin \hat{\gamma}_{m} \\
\sin \hat{\gamma}_{m} & \cos \hat{\gamma}_{m}
\end{array}\right]\left[\begin{array}{c}
i_{\alpha r} \\
i_{\beta r}
\end{array}\right] .
$$

Equation (3) gives $P_{e}$ in function of the stator and rotor currents and the rotor estimated position angle $\hat{\gamma}_{m}$. The rotor position angle $\gamma_{m}$ can be evaluated using the stator and rotor measured currents and the active power transferred across the air gap that should be evaluated by the reference model.

\subsection{Implementation on the Stator Reference Frame. Equation}

(3) determines $P_{e}$ in function of the measurable stator voltages and currents, of the rotor current and of the position that should be estimated. The rotor and stator currents are measured in different reference frames, that is, the stator currents and voltages are measured in the stator reference frame and the rotor current on the rotor reference frame.

Figure 2 shows the block diagram of the rotor position detection system proposed in this paper. The complex exponential represents the reference frame transformation (4) and the circle with a dot represents the inner product of vectors. In Figure 2, the error $\varepsilon_{r}$ is controlled by a hysteresis controller with a window gap (delta) equal to zero. A PI controller can also be used.

2.4. Implementation on the Rotor Reference Frame. The adaptive model can be also written on the rotor reference frame. In this case the electromotive force (2) should be transformed to the rotor variables and a similar equation as (3) should be applied.

2.5. Hysteresis Controller Implementation. The difference between the outputs of the two models is the error $\varepsilon_{r}$ that is defined by

$$
\varepsilon_{r}=P_{e s}-P_{e r} .
$$

The error $\varepsilon_{r}$ is the input of a hysteresis controller that switches on or off when it is positive or negative $[16,17]$.

It was concluded that the best value is delta $=0$. The higher switching frequency of the hysteresis controller with delta $=0$ does not give rise to chattering problems because it is limited to the sampling frequency used and this does not give rise to any power electronics commutation. The behavior of the hysteresis controller only results in adjustments of phase in software. The output of the hysteresis comparator will switch between two determined values and will be integrated leading to the estimated position $\hat{\gamma}_{m}$, as shown in Figure 2.

Because the output of the integrator is the estimated rotor position, the input will be the speed, that is, the output of the hysteresis comparator is, in average and in steady state, the speed of the machine. So, the output values of the hysteresis controller are the theoretical limits of the speed range of the estimator. Because the speed range of the DFIG is usually set on $[0.7,1.3]$ p.u., in order to establish the appropriate speed range of the estimator, the output of the hysteresis comparator was set in $[0,2]$ p.u. .

The controller adjusts the estimated position angle in order to obtain equal values for $P_{e}$ using the reference model and the adaptive model. In steady state the error is null and so the position is the one that equals the two values of $P_{e}$. If, in a considered instant of time, the estimated value of the rotor position gives a $P_{e}$ value smaller that the reference value, the hysteresis controller gives a positive output speed leading to an increase of the position, and so the error will become smaller in the next sampling period. If the adaptive model value of $P_{e}$ is bigger than the reference value, the output of the hysteresis controller will be zero leading to a fixed position of the estimated rotor position. It is important to refer that the reference model does not depend on the accuracy of the flux estimator.

The stator reference frame implementation was adopted on the results presented in this paper.

The major advantages of the proposed method are that it is not necessary to estimate rotor or stator fluxes, it uses measured voltages and currents, and when a hysteresis controller is used it is not necessary to evaluate any PI parameter.

\section{Stability Analysis}

3.1. Modeling. In this section the system stability is analyzed using a small signal model. This model can be obtained from the block diagram of Figure 2 considering that the stator and rotor currents are in steady state and there is a small perturbation on the estimated position angle, as shown in Figure 3(b). The vector diagram of Figure 3 shows the rotor current as well as the electromotive vector considering that the estimated position is equal to the actual position. In Figure 3(b) there is an error on the estimation of the rotor position. Therefore, there will be an error of equal value on the rotor current on the stator reference frame. This new vector will be used for evaluation of the $P_{e r}$. 


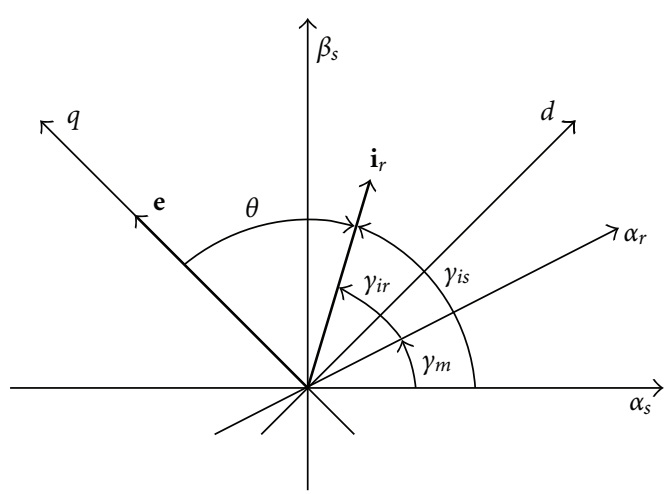

(a) Vector diagram without errors on the estimation

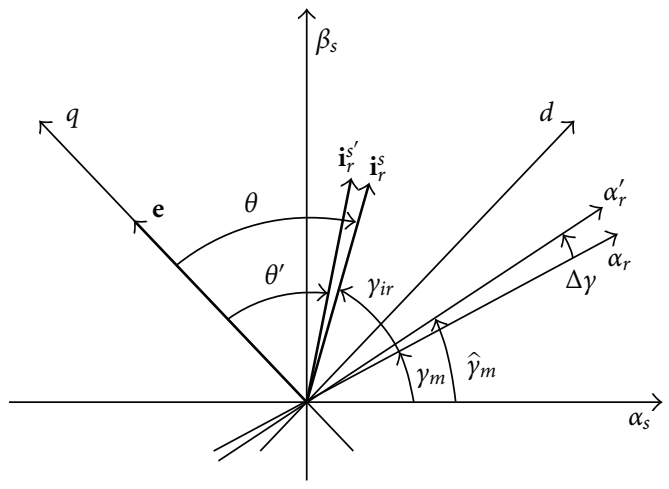

(b) Vector diagram with errors on the estimation

Figure 3: Vector diagrams.

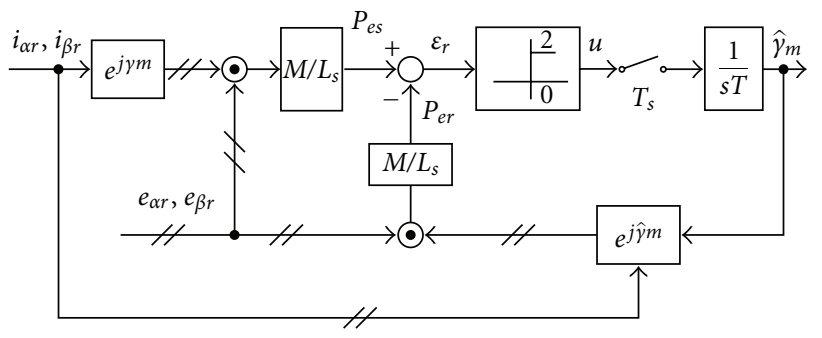

FIGURE 4: Bock diagram for stability study.

Adopting the complex notation of space vectors, the adaptive model can be written in the form

$$
P_{e r}=-\frac{M}{L_{s}} \operatorname{Re}\left\{\mathbf{e}\left(\mathbf{i}_{r} e^{j \hat{\gamma}_{m}}\right)^{*}\right\} .
$$

The reference model is written in terms of stator voltages and currents. Considering that these are measured variables related with the active power that crosses the air gap and the electrical equations of the machine, this reference model can have a similar form as (6), but using the actual rotor position and not the estimated position. So

$$
P_{e s}=-\frac{M}{L_{s}} \operatorname{Re}\left\{\mathbf{e}\left(\mathbf{i}_{r} e^{j \gamma_{m}}\right)^{*}\right\} .
$$

Using (6) and (7) and Figure 2, the appropriate model for the stability studies is found and presented in Figure 4. In this

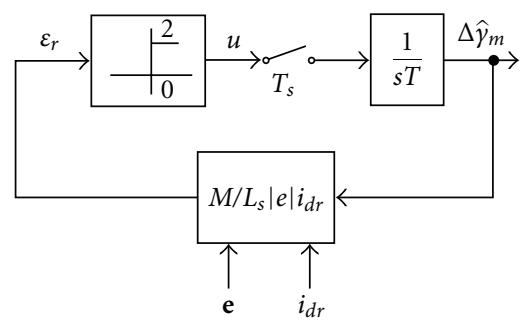

FiguRE 5: Bock diagram for small perturbation.

figure the complex exponential blocks represent reference frame rotations and the circles with a dot in the center represent the inner product.

The error $\varepsilon_{r}$ can be obtained using

$$
\begin{aligned}
\varepsilon_{r} & =P_{e s}-P_{e r} \\
& =-\frac{M}{L_{s}} \operatorname{Re}\left\{\mathbf{e}\left(\mathbf{i}_{r} e^{j \gamma_{m}}\right)^{*}\right\}-\left(-\frac{M}{L_{s}} \operatorname{Re}\left\{\mathbf{e}\left(\mathbf{i}_{r} e^{j \hat{\gamma}_{m}}\right)^{*}\right\}\right) .
\end{aligned}
$$

After a mathematical manipulation and considering the vector diagram of Figure 3, the following expressions are obtained:

$$
\varepsilon_{r}=\frac{M}{L_{s}}|e|\left|i_{r}\right| \sin \theta \Delta \hat{\gamma}_{m}
$$

or

$$
\varepsilon_{r}=\frac{M}{L_{s}}|e| i_{d r} \Delta \hat{\gamma}_{m},
$$

where $\Delta \hat{\gamma}_{m}$ is the perturbation of the estimated rotor position that is defined as

$$
\Delta \hat{\gamma}_{m}=\hat{\gamma}_{m}-\gamma_{m}=-\left(\theta-\theta^{\prime}\right) .
$$

The block diagram for small perturbations, Figure 5, is obtained using Figure 4 and (8)-(11).

3.2. Stability Analysis. The analysis of the stability can be performed using the sliding mode criterion.

According to the stability condition of sliding mode systems, the stability is guaranteed when the product of the error $\varepsilon_{r}$ by its derivative is always negative [17]. The fulfillment of this inequality ensures the convergence of the system state trajectories to the sliding surface $\varepsilon_{r}=0$. So,

$$
\begin{gathered}
\varepsilon_{r}>0 \longrightarrow u=2 \longrightarrow \frac{d \varepsilon_{r}}{d t}=\frac{M}{L_{s}}|e| I_{d r} \frac{2}{T}, \\
\varepsilon_{r}<0 \longrightarrow u=0 \longrightarrow \frac{d \varepsilon_{r}}{d t}=0 .
\end{gathered}
$$

From (12) it is clear that the system will be marginally stable when

$$
I_{d r}<0 .
$$

Equations (12) are valid for the analysis in continuous time when no sampling interval is considered. When, in a $T_{s}$ 

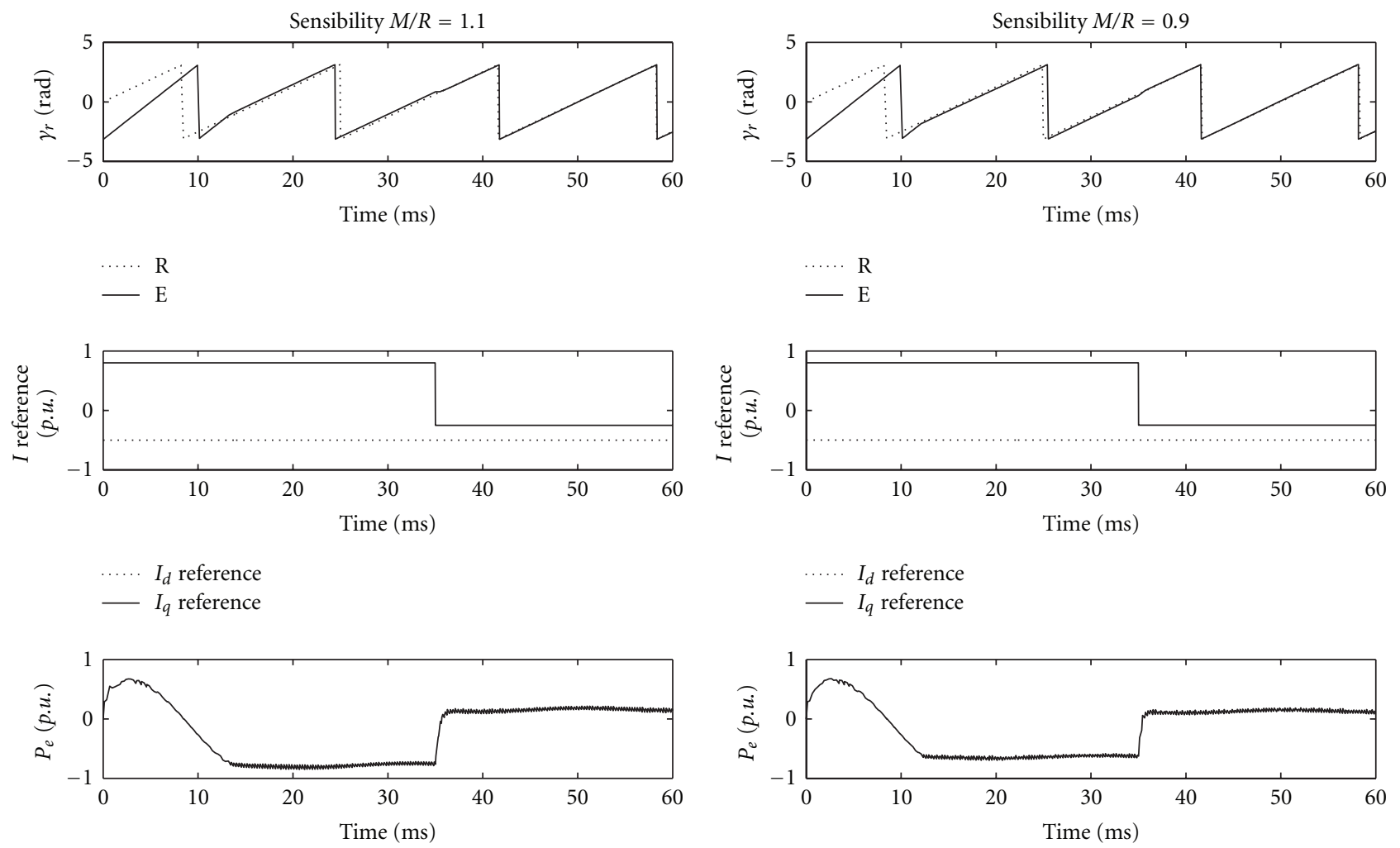

(a) The $M / L_{s}$ parameter is bigger than the real

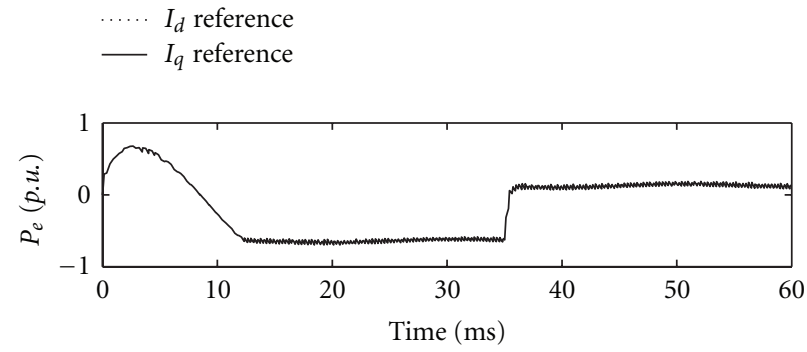

(b) The $M / L_{s}$ parameter is smaller than the real

FIGURE 6: Real (R) and estimated (E) position for rated current and $M / L_{s}$ error.

interval, the first condition occurs (12), that is, $u=2$, the estimated position will increase at a constant speed equal to 2 p.u., that is, greater than the speed of the machine $(0.7<$ $\omega_{m}<1.3$ p.u. $)$. According to (11) the $\Delta \hat{\gamma}_{m}$ will increase, and so the $\varepsilon_{r}$ will decrease if $I_{d r}<0$ (10).

Conversely, when the second condition occurs, $u=0$, the estimated position will be constant within this time interval. Furthermore, the actual position of the machine will be increased by $\omega_{m} T_{s}$, the $\Delta \hat{\gamma}_{m}$ will decrease, and so $\varepsilon_{r}$ will increase if $I_{d r}<0$, confirming that the condition of stability is given by (13).

This stability border was verified experimentally and using simulation programs when high sampling frequencies are used. Because the system is a sampled system, the sampling frequency reduces the stability area near the border.

\section{Sensibility Analysis}

A MatLab/Simulink routine was constructed to determine the behavior of the proposed estimator included in the DFIG. It is also used for the study of sensibility to parameters.

The performance of this system depends on the measured quantities and only on two parameters: the stator resistance and the parameter $M / L_{s}$. The resistance parameter has a small influence because the corresponding voltage drop is small compared with the voltage applied to the stator circuits. Even in the prototype used in the laboratory this quantity is about $6 \%$. For bigger machines, this value is about $1 \%$. In this case the quantity that is important for sensibility analysis is the parameter $M / L_{s}$.

In Figure 6 the starting on the fly is shown. The initial real and estimated positions are opposite, that is, they are zero and $-\pi$, respectively. The transient to obtain the correct position is clearly shown and lasts about $10 \mathrm{~ms}$.

If a considerable error on the $M / L_{s}$ parameter exists, for example, $10 \%$, there is a difference between the estimated and the actual position as shown in Figure 6(a). This error depends on the currents as shown in this figure. If a lower value of $M / L_{s}$ is used, the sign of the error changes, as shown in Figure 6(b).

It can be concluded that, although the behavior of the system is dependent on the parameter $M$, it allows reasonable errors on this parameter leading to acceptable responses.

\section{Experimental Results}

This section presents some experimental results obtained in a prototype constructed for this purpose using a $3.2 \mathrm{~kW}$ wound induction machine. The estimation algorithm is implemented in a Microchip dsPIC30F4011. To obtain experimental results in real time, four PWM output channels with simple RC filters were used. The actual rotor position is also measured using an encoder with a 4096 step resolution and another dsPIC30F4011. Because a 2 pole pairs motor 


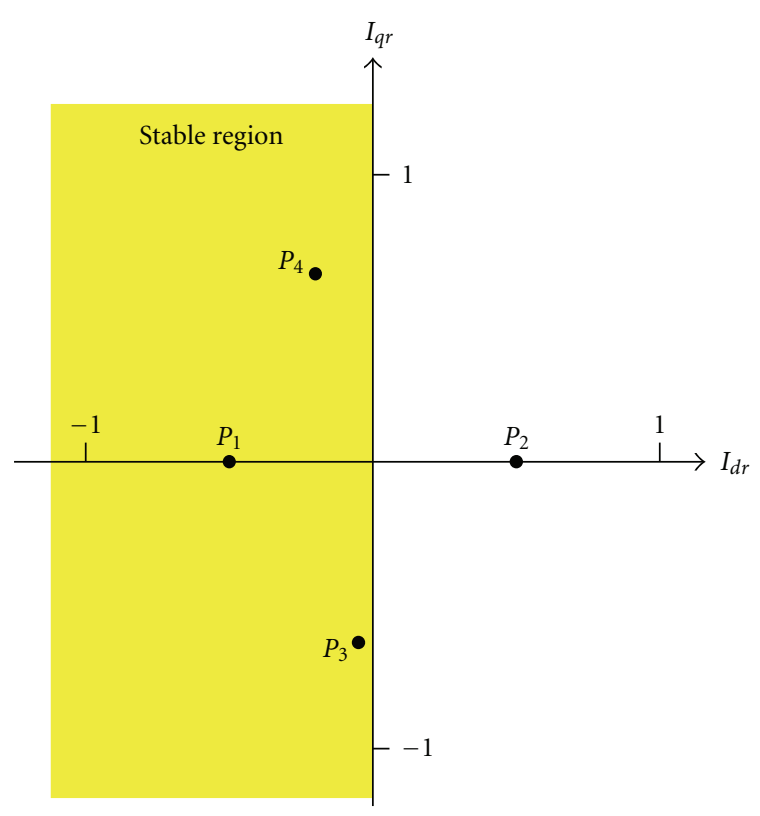

(a) Definition of the points $P_{1}$ to $P_{4}$
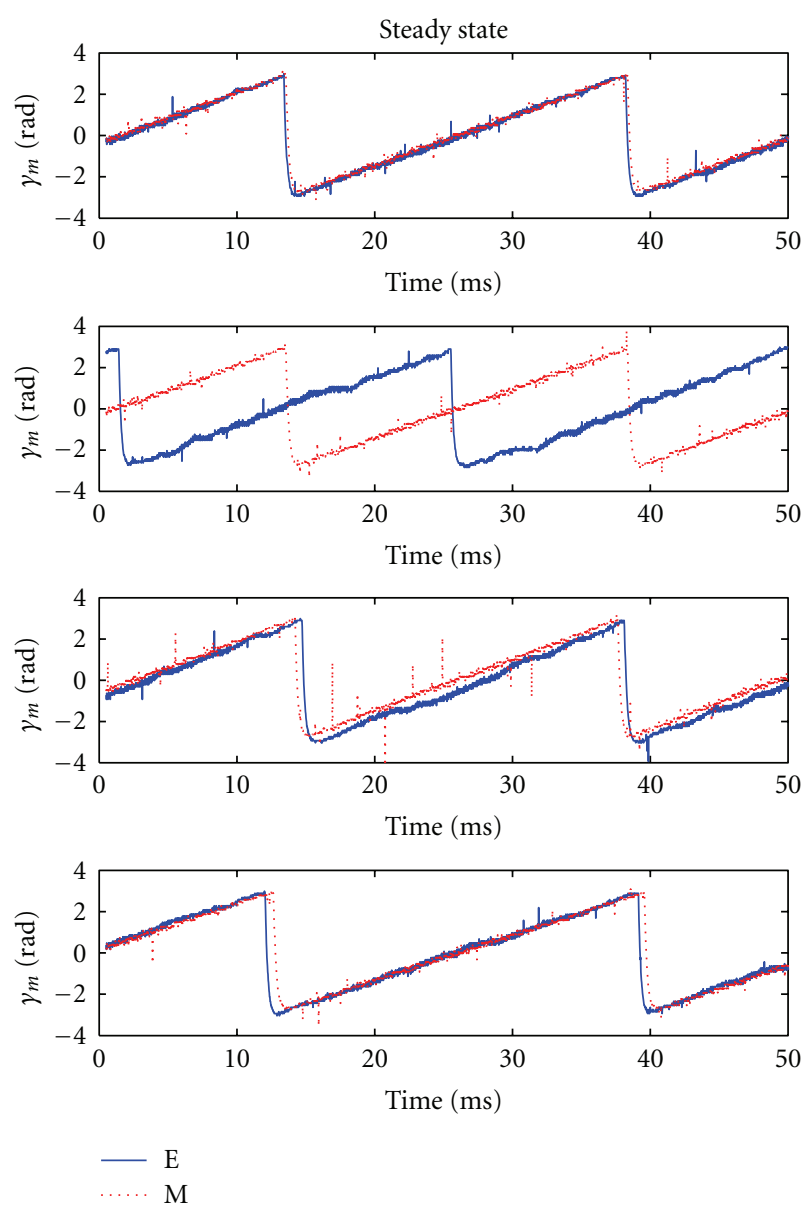

(b) $P_{1}$ to $P_{4}$ from top to bottom

Figure 7: Steady-state results for different working points.
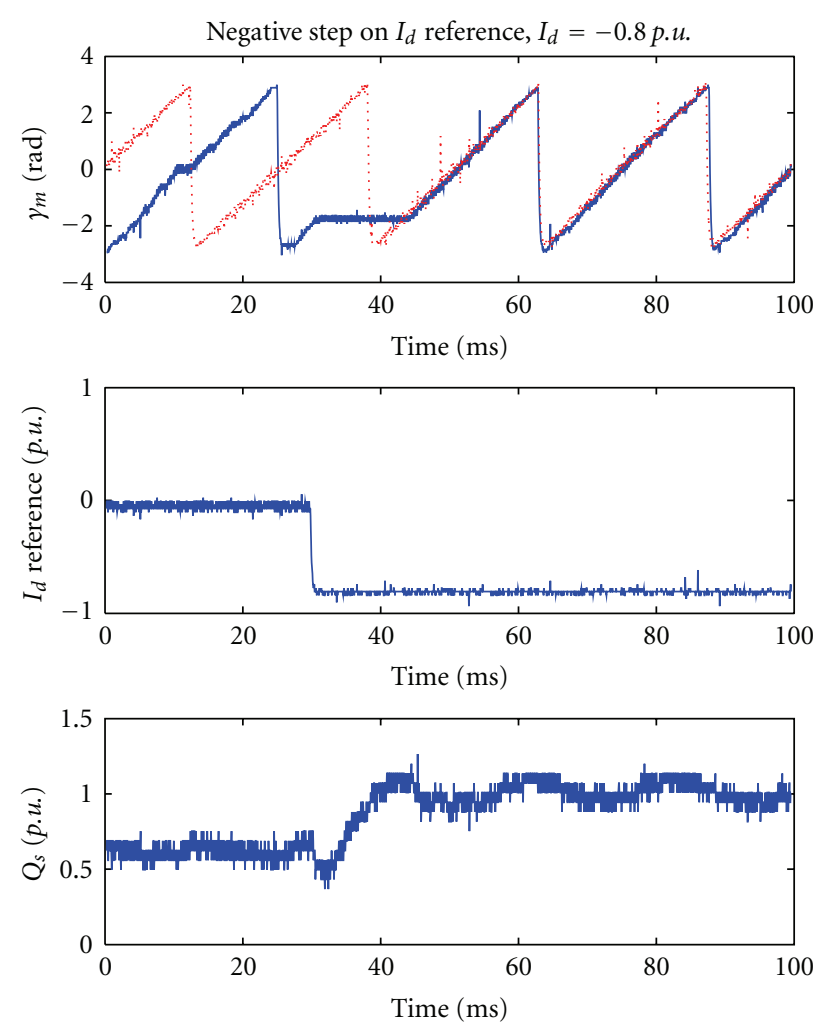

$-\mathrm{E}$

Figure 8: Negative step response $I_{d}$.

was used, the electrical position resolution decreases to 2048, which is enough. The results are presented using radian values.

Figure $7(\mathrm{~b})$, obtained with the hysteresis controller implemented on the stator reference frame, shows the estimated position obtained $\hat{\gamma}_{m}$ and the real position obtained with the encoder for the four points defined in Figure $7(\mathrm{a})$.

Point $P_{1}$ is a stable point far from the stability margin. Point $P_{1}$ is an unstable point. The system produces a waveform that is in phase opposition with the measurement. Points $P_{3}$ and $P_{4}$ are near the border. It is shown that the performance degrades when the operating point is near the stability border.

It was verified that the system works considerably well even when low rotor currents are considered. This is an advantage of this system when compared with others.

Figure 8 shows the response to a negative step on the $I_{d}$ rotor current reference. A stable position is obtained and it can be seen the starting on the fly because the system starts from a point of zero rotor current. It lasts about half period as expected.

Figure 9 shows the response to a step on the $I_{d}$ reference. This figure was obtained using negative values for the direct and quadrature current.

Figure 10 shows the response to a positive step on the quadrature current and when the direct current is small. Some oscillation on $P_{e}$ can be observed. 

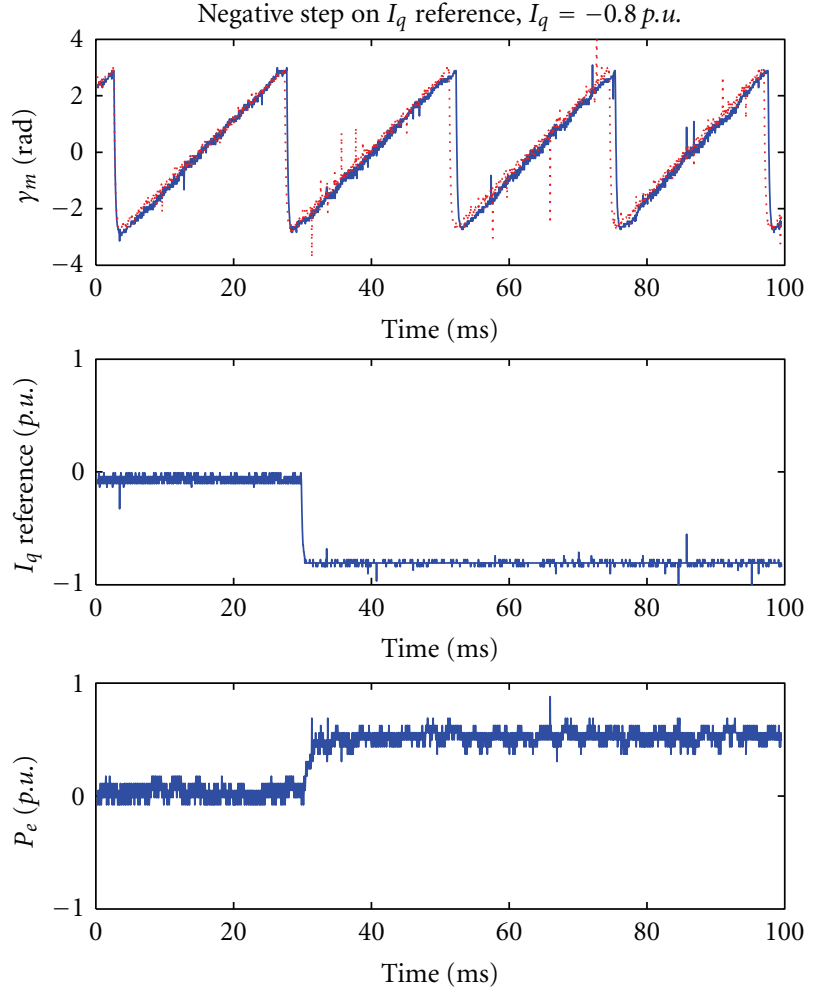

$-\mathrm{E}$

M

Figure 9: Negative step response to $I_{q}$.
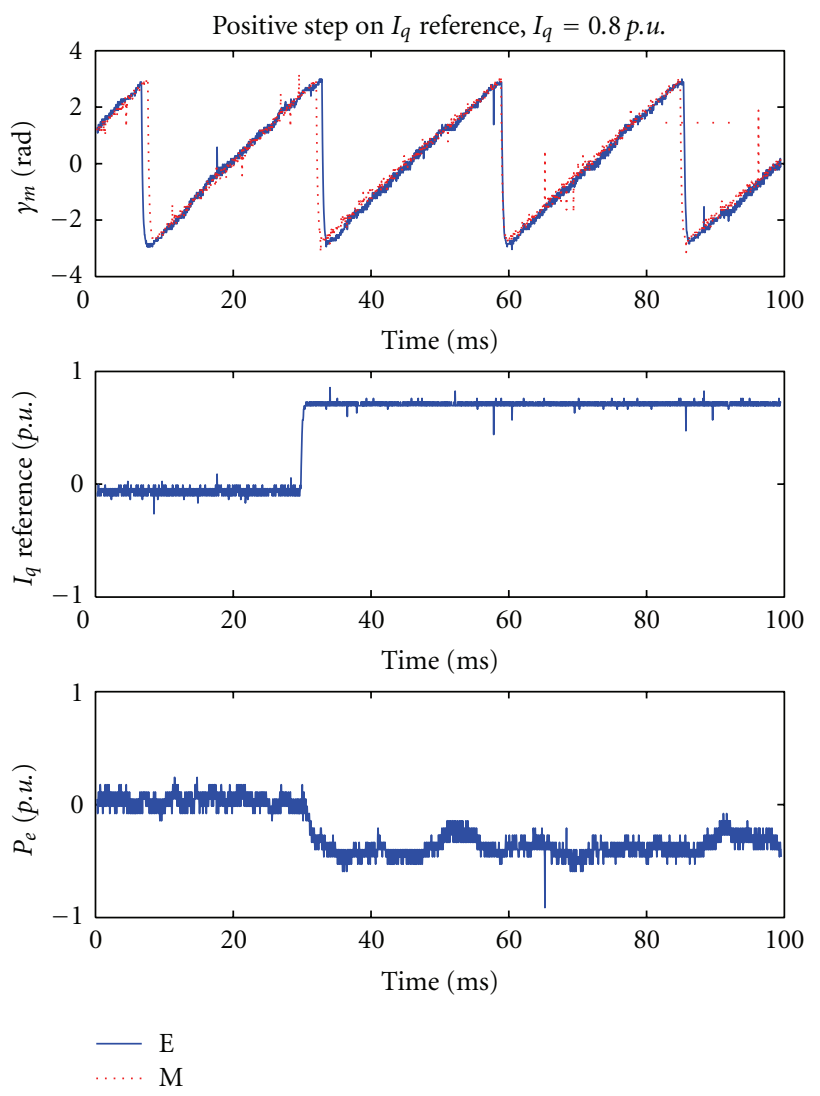

FIGURE 10: Response to a positive step on $I_{q}$.

\section{Conclusions}

The paper presents a sensorless system for the estimation of the rotor position of the DFIG. The proposed sensorless algorithm fulfils the requirements of this system in the applications when a restricted speed range is necessary and when no reactive power should be delivered from the rotor. The starting on the fly of the system is established easily. Although the performance of the system is dependent on the $M / L_{s}$ parameter, it was shown that the system works acceptably well with low currents as $3 \%$ of rated rotor current.

\section{Appendix}

\section{Parameters of the DFIG}

Induction Machine: stator $380 \mathrm{~V}, 8.1 \mathrm{~A}$, rotor $110 \mathrm{~V}, 19 \mathrm{~A}$, $3.2 \mathrm{~kW}$, four poles, $1400 \mathrm{rpm}, L_{s}=1.62$ p.u., $M=1.17$ p.u., $r_{s}=0.06$ p.u.

\section{Nomenclature}

$\begin{array}{ll}\text { General } & \\ L_{s}, M: & \text { Stator and mutual inductance, } \\ r_{s}: & \text { Stator resistance, } \\ i: & \text { Stator or rotor current, } \\ u: & \text { Stator voltage, } \\ P_{e}: & \text { Power transferred in the air gap, } \\ P_{e s}: & \text { Power across the air gap using the reference } \\ & \text { model, } \\ P_{e r}: & \text { Power across the air gap using the adaptive } \\ & \text { model, } \\ p_{f e}: & \text { Stator magnetic losses, } \\ \gamma_{s}: & \text { Position of the stator flux vector, } \\ \gamma_{m}: & \text { Electrical position of the rotor, } \\ \varepsilon_{r}: & \text { Error, } \\ \omega_{s}: & \text { Electrical frequency of the ac mains, } \\ \mathbf{i}_{s}: & \text { Stator current vector, } \\ \mathbf{i}_{r}: & \text { Rotor current vector, } \\ \mathbf{u}_{s}: & \text { Stator voltage vector, } \\ \mathbf{e}: & \text { Electromotive force vector, } \\ \text { Superscripts } & \\ \wedge: & \text { Estimated value, } \\ s, r: & \text { Stator or rotor reference frame, } \\ \text { Subscripts } & \\ \alpha, \beta: & \text { Usual } \alpha \beta \text { variables, } \\ d, q: & \text { Variables on a common moving reference } \\ s, r: & \text { frame, } \\ & \text { Stator or rotor quantities. }\end{array}$

\section{Acknowledgments}

This work was supported in part by Center for Innovation in Electrical and Energy Engineering (CIEEE) of IST/TULisbon and Programa Operacional da Sociedade do Conhecimento (POSC). 


\section{References}

[1] R. Pena, J. C. Clare, and G. M. Asher, "Doubly fed induction generator using back-to-back PWM converters and its application to variable-speed wind-energy generation," IEE Proceedings: Electric Power Applications, vol. 143, pp. 231-241, 1996.

[2] R. Datta and V. T. Ranganathan, "A simple position-sensorless algorithm for rotor-side field-oriented control of woundrotor induction machine," IEEE Transactions on Industrial Electronics, vol. 48, no. 4, pp. 786-793, 2001.

[3] E. Bogalecka, "Power control of a double fed induction generator without speed or position sensor," in Proceedings of the 5th European Conference on Power Electronics and Applications, vol. 8, chapter 50, pp. 224-228, September 1993.

[4] E. Bogalecka and Z. Krzeminski, "Sensorless control of double fed machine for wind power generators," in Proceedings of the 10th International Conference on Power Electronics and Motion Control (EPE-PEMC '02), Dubrovnik, Croatia, 2002.

[5] Z. Krzeminski, A. Popenda, M. Melcer, and P. Ladach, "Sensorless control system of double fed induction machine with predictive current controller," in Proceedings of the European Conference on Power Electronics and Applications (EPE '01), Graz, Austria, 2001.

[6] L. Xu and W. Cheng, "Torque and reactive power control of a doubly fed induction machine by position sensorless scheme," IEEE Transactions on Industry Applications, vol. 31, no. 3, pp. 636-642, 1995.

[7] L. Morel, H. Godfroid, A. Mirzaian, and J. M. Kaufmann, "Double-fed induction machine: converter optimization and field oriented control without position sensor," IEE Proceedings: Electric Power Applications, vol. 145, no. 4, pp. 360-368, 1998.

[8] B. Hopfensperger, D. J. Atkinson, and R. A. Lakin, "Statorflux-oriented control of a doubly-fed induction machine with and without position encoder," IEE Proceedings: Electric Power Applications, vol. 147, no. 4, pp. 241-250, 2000.

[9] R. Cárdenas, R. Peña, G. Asher, J. Clare, and J. Cartes, "MRAS observer for doubly fed induction machines," IEEE Transactions on Energy Conversion, vol. 19, no. 2, pp. 467-468, 2004.

[10] R. Cárdenas, R. Peña, J. Proboste, G. Asher, and J. Clare, "Rotor current based MRAS observer for doubly-fed induction machines," Electronics Letters, vol. 40, no. 12, pp. 769-770, 2004.

[11] R. Cárdenas, R. Peña, J. Proboste, G. Asher, and J. Clare, "Sensorless control of a doubly-fed induction generator for stand alone operation," in Proceedings of the 35th Annual IEEE Power Electronics Specialists Conference, pp. 3378-3383, Aachen, Germany, 2004.

[12] R. Peña, R. Cárdenas, J. Proboste, G. Asher, and J. Clare, "Sensorless control of doubly-fed induction generators using a rotor-current-based MRAS observer," IEEE Transactions on Industrial Electronics, vol. 55, no. 1, pp. 330-339, 2008.

[13] B. Shen, B. Mwinyiwiwa, Y. Zhang, and B. T. Ooi, "Sensorless maximum power point tracking of wind by DFIG using rotor position phase lock loop (PLL)," IEEE Transactions on Power Electronics, vol. 24, no. 4, pp. 942-951, 2009.

[14] B. Mwinyiwiwa, Y. Zhang, B. Shen, and B. T. Ooi, "Rotor position phase-locked loop for decoupled P-Q control of DFIG for wind power generation," IEEE Transactions on Energy Conversion, vol. 24, no. 3, pp. 758-765, 2009.
[15] G. D. Marques, V. Fernão Pires, S. Sousa, and D. M. Sousa, "Evaluation of a DFIG rotor position-sensorless detector based on a hysteresis controller," in Proceedings of the PowerEng Conference, Costa da Caparica, Lisbon, 2009.

[16] G. D. Marques, V. F. Pires, S. Sousa, and D. M. Sousa, "A DFIG sensorless rotor position detector based on a hysteresis controller," IEEE Transactions on Energy Conversion, vol. 26, no. 1, pp. 9-17, 2011.

[17] J. F. Silva and S. F. Pinto, "Control methods for switching power converters," in Power Electronics Handbook, M. H. Rashid, Ed., chapter 34, pp. 935-998, Elsevier, Academic Press, 2nd edition, 2006. 

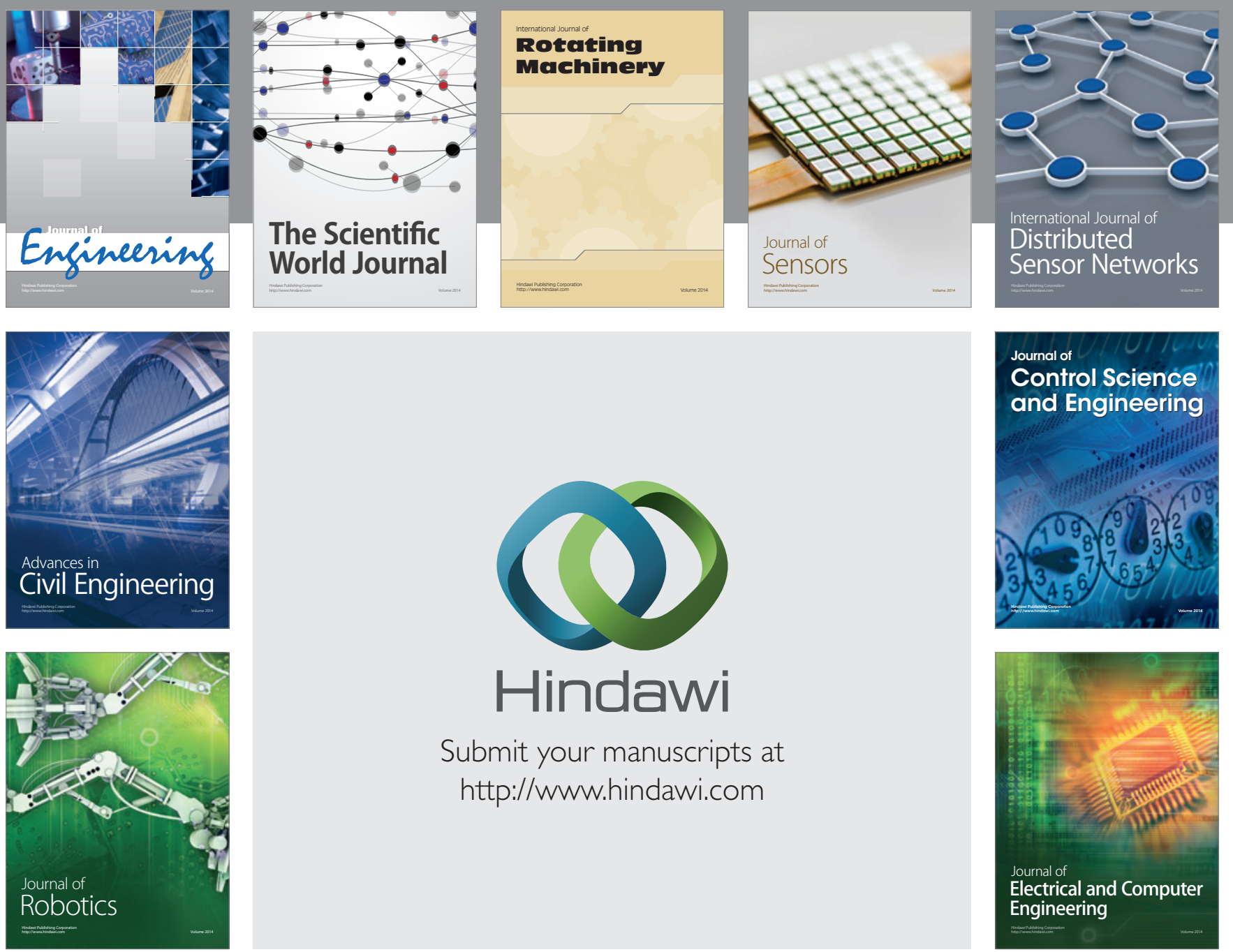

Submit your manuscripts at

http://www.hindawi.com
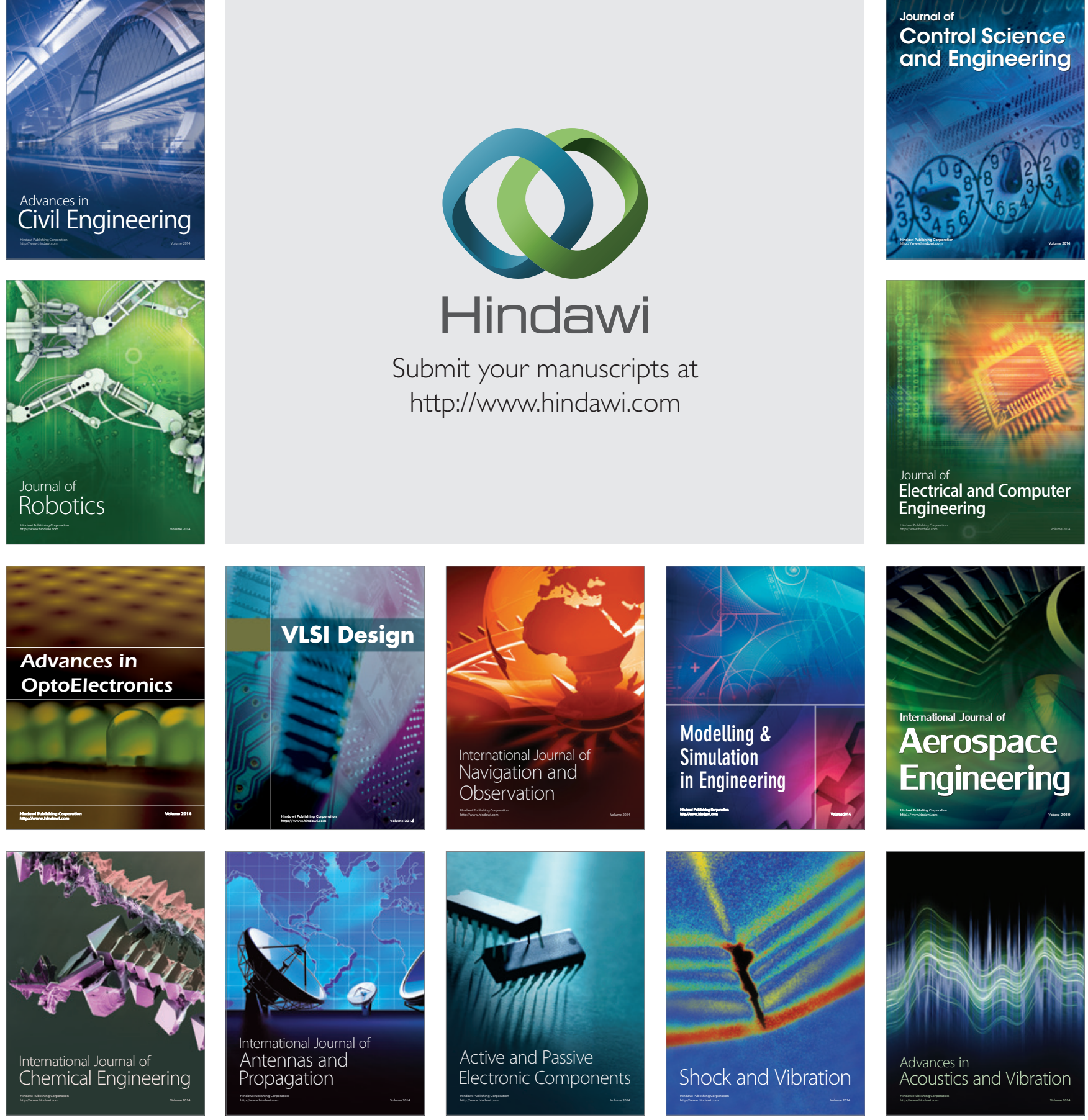